\title{
Analyzing of Student's Mathematical Reasoning Ability in Solving Mathematical Problem Based on Higher Order Thinking Skill (HOTS)
}

\author{
Susi Herawati ${ }^{1, *}$ Puspa Amelia ${ }^{2}$ \\ ${ }^{1,2}$ University of Bung Hatta \\ *Corresponding author. Email: susi.herawati@bunghatta.ac.id
}

\begin{abstract}
In this paper, we consider to analyzed the mathematical reasoning ability of students in solving mathematics problem based on Higher Order Thinking Skill (HOTS). The method of this research is qualitative descriptive. This research consisted of 12 subject. Based on the analysis that mathematic reasoning ability of students can be grouping into 3 categories, that are low, moderate and high groups. The results showed that $16.7 \%$ of students were categorized as having low reasoning, that is presenting a mathematical statement in writing, $16.7 \%$ of students were categorized as having moderate reasoning, that is able to make a conjecture and perform mathematical manipulation, and $66.7 \%$ of students were categorized as having high reasoning, which is able to make a conjecture, to perform a mathematical manipulation, to provide the reasons or evidence for the solution and drawing a conclusion.
\end{abstract}

Keywords: Mathematical, Reasoning Ability, HOTS.

\section{INTRODUCTION}

Reasoning is a very important aspect of mathematical ability in teaching and learning of mathematic [1] . One of the goals of mathematics listed in Permendikbud Number 58 Year 2014 is to use reasoning in nature,manipulate mathematics both in simplification, and analyze the existing components in problem solving in the context of mathematics and others [2]. Furthermore [3] stated that the development of mathematics is inseparable from reasoning and proofing. In line with this, [4], [5], [6], stated between mathematics and reasoning cannot be separated one another because understanding mathematics requires reasoning which can be trained through mathematical material.

According to [7] reasoning is defined as the process of drawing conclusions on the basis of evidence or assumed assumptions. Reasoning is a process of drawing conclusions from information that is not static. The ability of mathematical reasoning is part of mathematical skills which are used in all phases and different activities and also relate to mathematical literacy. Reasoning ability is rooted in logical thinking process that explores and connects basic of the problem so that it can generate a reasonable conclusion, examine the truth, or prove the truth of statement or solution. Improving the ability of mathematical reasoning provides benefits that can form good mindset for students to deal with real-world problems either now or when they have joined into the community.
Mathematical reasoning is important because it makes unique features applied in mathematics as a subject [8]. Once students are able to apply some of the unique features of mathematics, then they are able to solve problems that require them to generalize, apply abstract thinking and also simplify. Therefore, mathematical reasoning is very useful for problems solving [9]. The ability of mathematical reasoning is the ability to think or undertstand the problem of mathematics logically in order to obtain completion, sorting out what is important and not important in solving a problem that and explain, or give the reasons for the settlement of a problem.

One way to measure student's mathematical reasoning skills by using problem solving. Mathematical reasoning is part of the problem-solving process that involves thinking and reasoning skills of students in seeking alternative solutions to problems [10]. Problem solving is a central to inquiry and application and should be interwoven throughout the mathematics curriculum to provide a context for learning and applying mathematical ideal". Polya in [10] suggested that problem solving is a complex process one, which is consist of four phases : "understanding the problem, devising a plan, carrying out the plan, and looking back".

Problem solving question that we used in this research based on Higher Order Thinking Skills (HOTS). Brookhart categorized the top three of cognitive processes in Bloom's taxonomy, namely analyzing, evaluating, and creating as higher order 
thinking processes [11]. Higher Order Thinking Skills are the ability of students to connect learning with other things that have not been taught which includes the ability to analyze, evaluate, and create.

The indicators of mathematical reasoning ability in this study can be seen in the table 1 .

Table 1. The Indicators of Mathematic's Reasoning Ability

\begin{tabular}{|c|c|c|}
\hline $\begin{array}{c}\text { Reasoning Mathematical } \\
\text { Abiliy } \\
\end{array}$ & Descriptor & Problem Solving Steps \\
\hline \multirow{3}{*}{$\begin{array}{l}\text { Ability to present } \\
\text { mathematical statement } \\
\text { orally, in writing, pictures } \\
\text { and diagram. }\end{array}$} & Write down what is known and asked & \multirow{3}{*}{$\begin{array}{l}\text { Understanding the } \\
\text { problems }\end{array}$} \\
\hline & $\begin{array}{l}\text { Convey what is known and asked } \\
\text { verbally }\end{array}$ & \\
\hline & $\begin{array}{l}\text { Describe what is known or not in } \\
\text { diagrammatic form }\end{array}$ & \\
\hline $\begin{array}{l}\text { Ability to make a } \\
\text { conjecture }\end{array}$ & $\begin{array}{l}\text { Asking questions about problem } \\
\text { solving }\end{array}$ & Devising a plan \\
\hline $\begin{array}{l}\text { Ability to perform } \\
\text { mathematical } \\
\text { manipulation }\end{array}$ & $\begin{array}{l}\text { Performs algebraic manipulation on } \\
\text { solving mathematical problems }\end{array}$ & \multirow{3}{*}{ Carrying out the plan } \\
\hline \multirow{2}{*}{$\begin{array}{lr}\text { Ability to } & \text { draw } \\
\text { conclusions, } & \text { compile } \\
\text { evidence against } & \text { several } \\
\text { solutions } & \\
\end{array}$} & Compile proof of mathematics problem & \\
\hline & $\begin{array}{l}\text { Provide reasons or evidence for } \\
\text { solutions }\end{array}$ & \\
\hline $\begin{array}{lr}\begin{array}{l}\text { Ability to } \\
\text { conclusions } \\
\text { statement }\end{array} & \begin{array}{r}\text { make } \\
\text { from }\end{array} \\
\end{array}$ & Make a conclusion for statements & \multirow[b]{3}{*}{ Looking back } \\
\hline The validity an argument & $\begin{array}{l}\text { Check the answer that have been } \\
\text { obtained }\end{array}$ & \\
\hline $\begin{array}{l}\text { Ability to find patterns or } \\
\text { properties of a } \\
\text { mathematical } \\
\text { phenomenon to make } \\
\text { generalizations }\end{array}$ & $\begin{array}{l}\text { Find patterns or properties of } \\
\text { mathematical phenomena to make } \\
\text { generalization }\end{array}$ & \\
\hline
\end{tabular}

Basically, every math problem solving requires reasoning skills. Through reasoning, students are expected to see that mathematics is a study that makes sense or logical. Integrating HOTS in mathematics learning can be hampered by a number of factors, one of which is the limitation of teachers understanding about HOTS [12]. Teachers still think that students who have high abilities can be given high level problems. Therefore, student teacher candidates need to be prepared in order to have high mathematical reasoning skills and be able to design HOTS-based problems.

Based on the analysis of student's test result in solving problems, the real analysis shows that $50 \%$ of students are not able to solve problems well because they are not able to understand the problem. This condition means they are not able to plan the solving of the problem. The facts that have been described showed that student's mathematical reasoning abilities are still low. So, this encourages researchers to describe student's mathematical reasoning skill in solving real analysis problems based on ability groups, namely high, moderate, and low thinking abilities. Students who have moderate and low thinking skills need to describe their mathematical reasoning, so that the lecturers can design appropriate learning models, in order to increase their study result.

\section{RESEARCH AND METHOD}

This research was a qualitative descriptive research. Participants of this study were 12 students of the fifth semester in mathematic education program, Bung Hatta University, in academic year 2019/2020. The data collection techniques employed mathematical reasoning test and interview guidelines. The reasoning test instrument consisted of five items that had been tested content validity through expert judgment. The fifth test questions were used to measure seven determined mathematical reasoning indicators, its namely 1) present mathematical statement in writing; 2) making conjecture; 3) performing mathematical manipulation; 4) drawing conclusions, compiling evidence, giving reasons or evidence to guarantee the validity of the solution; and 5) making conclusions; 6) validity an argument; 7) finding patterns or properties of the mathematical phenomenon to make a generalization.

The test result was analyzed by counting the score of each questions to assess student's works on mathematical reasoning ability. After that we groups it in three categories, as shown on the following table 2.

Table 2. Grouping Criteria of Reasoning Mathematical Ability

\begin{tabular}{|l|l|}
\hline \multicolumn{1}{|c|}{ Grouping Criteria } & \multicolumn{1}{c|}{$\begin{array}{c}\text { Cognitive } \\
\text { groups }\end{array}$} \\
\hline Score $\geq$ mean + deviation standard & High \\
\hline $\begin{array}{l}\text { Mean }- \text { deviation standard } \leq \text { Score }< \\
\text { mean }+ \text { deviation standard }\end{array}$ & Moderate \\
\hline Score $<$ mean - deviation standard & Low \\
\hline
\end{tabular}

\section{RESULT AND DISCUSSION}

Reasoning mathematical test was given to subjects which consist of 12 students. The results of the descriptive analysis in the reasoning ability tests are presented in table 3 below.

Table 3. Data Description of Resoning Mathematical Test

\begin{tabular}{|l|l|}
\hline \multicolumn{1}{|c|}{ Data Description } & Result Data \\
\hline Maximum score & 68 \\
\hline Minimum score & 8 \\
\hline Average & 37,17 \\
\hline Deviation Standard & 17.37 \\
\hline
\end{tabular}


Based on table 3, there were students with the lowest score of 8 and the highest score was only 68 from the maximum score of 100 . The average score was 37.17 and the deviation standard was 17.37. Based on the average score, it showed that student's mathematical reasoning ability was still far below the expectation. After calculating the mean and standard deviation of the test scores, then we grouping the subjects consist of three level, namely, high, moderate, and low groups with the following results.

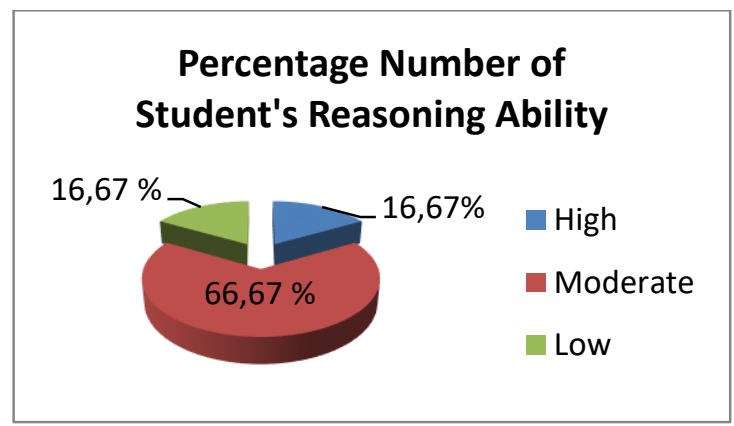

Figure 1. Percentage number of student's group

Based on figure 1, the result showed that $16.7 \%$ of students were categorized as having high reasoning, $66.7 \%$ of students were categorized as having moderate reasoning, and $16.7 \%$ of students were categorized as having low . After that, we selected some subjects from each group as presented in table 4 below :

Table 4. Grouping of Subject

\begin{tabular}{|l|l|}
\hline \multicolumn{1}{|c|}{ Subject Groups } & \multicolumn{1}{|c|}{$\begin{array}{c}\text { Selected } \\
\text { Subject }\end{array}$} \\
\hline High & S4, S6 \\
\hline Moderate & S1, S3, S7 \\
\hline Low & S2, S5 \\
\hline
\end{tabular}

The sample of student's answer from each goups can be seen in the figure 2 , figure 3 , and figure 4 .

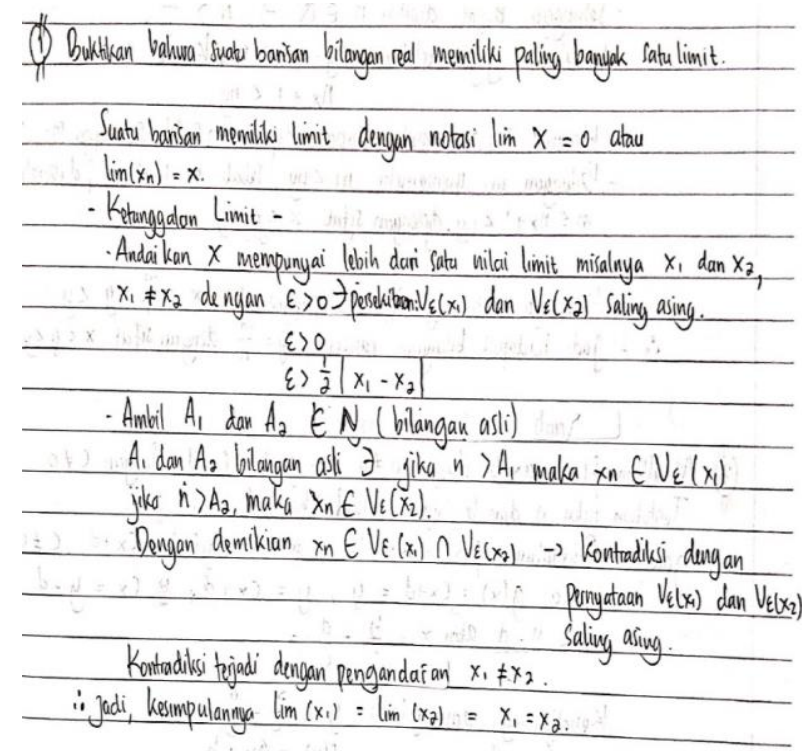

Figure 2. The answer of S4

4) Penyelesacan.

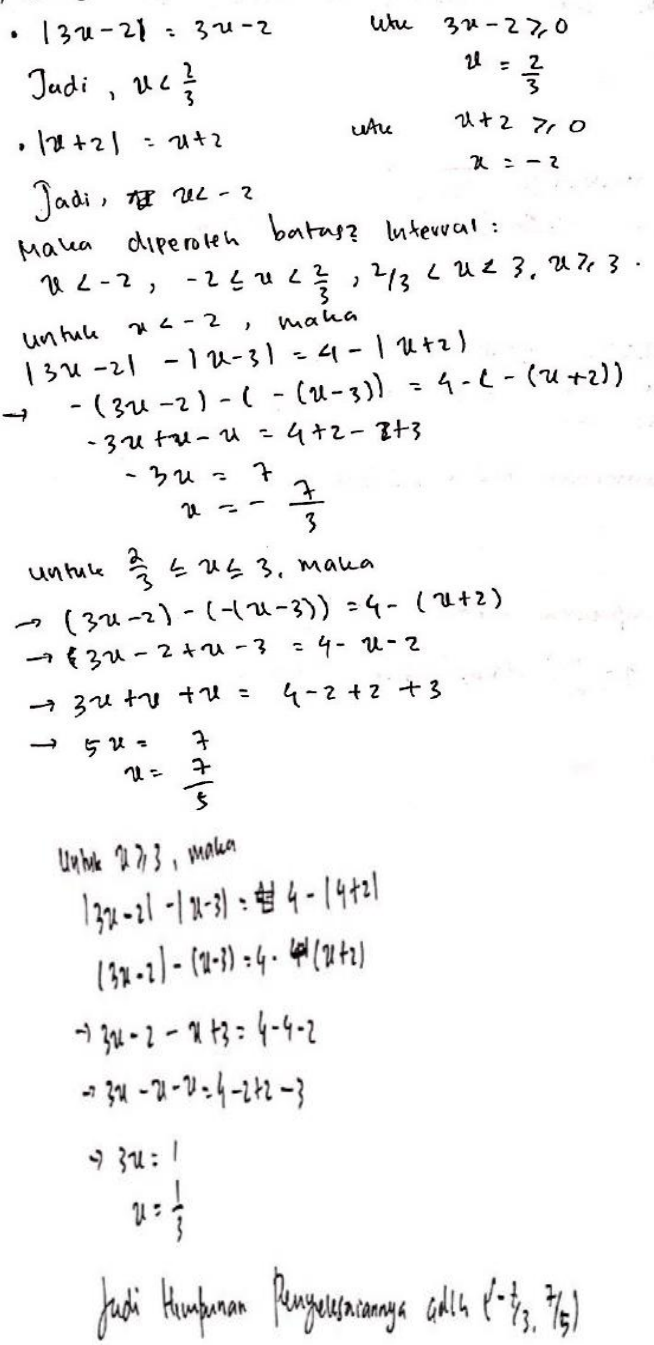

Figure 3. The Answer of S3 


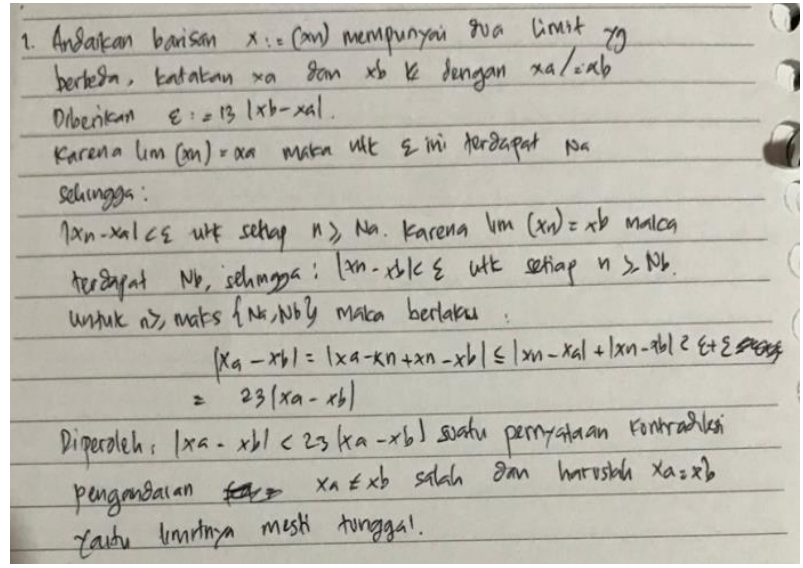

Figure 4. The Answer of S2

Based on table 4, we will analyze the reasoning mathematical ability of students from each indicators based on high, moderate, and low groups.

\subsection{Ability To Present Mathematical Statement Orally, In Writing, Pictures And Diagram}

For the question number 1 the students was given a question that is Prove that $\mathbb{R}$ sequence can have only one limit. From the answer of student which categorized in high group as we seen in figure 2, S4 was able to present mathematical statement in writing. At the beginning $\mathrm{S} 4$ assumed by contradiction that $X=\left(x_{n}\right)$ have more than one limit, that are $x_{1}$ and $x_{2}$. with $x_{1} \neq$ $x_{2}$. But S4 didn't wrote the definition of $\lim X=x_{n}$.

For the question number 4 the students was given a question that is Find all $x \in \mathbb{R}$ that satisfies the equation $|3 x-2|-|x-3|=4-|x+2|$. From the answer of student which categorized in moderate group as we seen in figure 3, S3 did not rewrite what the questions know and ask. The subject also did not write down the definition of absolute value first. It indicates that student didn't yet understand how to define of absolute value.

Furthermore, from the answer of student which categorized in low group as we seen in figure 4, the subject rewrites what the questions know and ask. The subject supposed that there is a sequence of real numbers $X=\left(x_{n}\right)$, and selected $x_{a}, x_{b}$ with $x_{a} \neq x_{b}$. But S4 didn't wrote the definition of $\lim X=x_{n}$. It indicates that student didn't yet understand how to define the dinition of limit.

\subsection{Ability To Make A Conjecture}

For the question number 1 the students was given a question that is Prove that $\mathbb{R}$ sequence can have only one limit. From the answer of student which categorized in high group as we seen in figure 2, S4 was able to make a conjecture. The subject used the definition of the environment in proving that a sequence has a single limit, take $A_{1}, A_{2} \in \mathbb{N} \ni$ if $n>A_{1}$ then $x_{n} \in V_{\varepsilon}\left(x_{1}\right)$ and if $n>A_{2}$ then $x_{n} \in V_{\varepsilon}\left(x_{2}\right)$. So $x_{n} \in V_{\varepsilon}\left(x_{1}\right) \cap V_{\varepsilon}\left(x_{2}\right)$.

For the question number 4 , the students was given a question that is Find all $x \in \mathbb{R}$ that satisfies the equation $|3 x-2|-|x-3|=4-|x+2|$. From the answer of student which categorized in moderate group as we seen in figure 3, S3 didn't yet understand to make a conjecture. The subject also did not write down the definition of absolute value first, so the subject was wrong in defining 2 absolute values contained by the equation, which was written $|3 x-2|=3 x-2$, for $3 x-2 \geq 0$ and $x<\frac{2}{3},|x+2|=x+2$, for $x+2 \geq 0$ and $x<-2$. This is not in accordance with the concept and definition of absolute value.

Furthermore, from the answer of student which categorized in low group as we seen in figure 4 , in answering question number 1 , The subject was able to make a conjecture, but S2 did not formulate that the proof is done in a way of contradiction. The subject only assumed that $X=\left(x_{n}\right)$ the sequence of real numbers and limit of $X$. The subject has taken the correct steps in solving the problem. However, the subject is less precise in defining $\lim \left(x_{n}\right)=x_{a}$ and $\lim \left(x_{n}\right)=x_{b}$.

\subsection{Ability To Perform Mathematical Manipulation}

From the answer of student in answering question number one which categorized in high group as we seen in figure 2, the student was able to perform set algebraic manipulation in solving problems. S4 used the definition of the $\varepsilon$ or $V_{\varepsilon}(x)$ in proving that a sequence has a single limit. S4 stated to take $A_{1}, A_{2} \in \mathbb{N} \ni$ if $n>$ $A_{1}$ than $x_{n} \in V_{\varepsilon}\left(x_{1}\right)$ and if $n>A_{2}$ then $x_{n} \in V_{\varepsilon}\left(x_{2}\right)$. So that $x_{n} \in V_{\varepsilon}\left(x_{1}\right) \cap V_{\varepsilon}\left(x_{2}\right)$.

For the question number 4, student which categorized in moderate group as we seen in figure 3, the subject is correct in determining the possible area of absolute value completion, namely yaitu $\quad x<$ $-2,-2 \leq x<\frac{2}{3}, \frac{2}{3}<x<3, x \geq 3$ and test the interval $x<-2$, that is $|3 x-2|-|x-3|=4-|x+2|$, so $x=-\frac{7}{3}$, and for interval $\frac{2}{3}<x<3,|3 x-2|-$ $|x-3|=4-|x+2|, \quad(3 x-2)-(-(x-3))=4-$ $(x+2), 5 x=7$, so $x=\frac{7}{5}$. The result obtained is the correct solution for the equation. Meanwhile, for the other 3 solution areas, S3 was wrong in describing the equation of its absolute value.

Furthermore, from the answer of student which categorized in low group as we seen in figure 4 , in answering question number 1 , based on the written answers, the subject has taken the right steps in solving the problem. However, the subject is not precise in defining $\lim \left(x_{n}\right)=x_{a}$ and $\lim \left(x_{n}\right)=x_{b}$. The subject is also wrong in choosing a quantity $\varepsilon$, that is, $\varepsilon=$ $\frac{1}{3}\left|x_{b}-x_{a}\right|$, for example it defines $\lim \left(x_{n}\right)=x_{a}$, then for $\varepsilon$ there is N_a so $\left|x_{n}-x_{a}\right|<\varepsilon$, for every $n \geq N_{a}$. 


\subsection{Ability To Draw Conclusions, Compile Evidence Against Several Solutions}

From the answer of student in answering question number one which categorized in high group as we seen in figure 2, The subject was able to prove that real numbers have one limit. Subjects devise appropriate strategies in carrying out proof using the contradiction method and the definition of the $\varepsilon$ or $V_{\varepsilon}\left(x_{2}\right)$. Based on the problem-solving steps taken, the subject can state the reasons for taking these steps, such as the subject choosing $A_{1} \in \mathbb{N}$ because for $n>A_{1}$ then $x_{n} \in V_{\varepsilon}\left(x_{1}\right)$.

For the question number 4 , student which categorized in moderate group as we seen in figure 3, The subject can compile evidence to determine the set of solutions to the absolute value equation, but the subject did not understand how to obtain the area for solving the absolute value equation. Based on the written problem solving, the subject does not provide reasons for several solutions, such as why the area for solving $x<-2$ is obtained.

Furthermore, from the answer of student which categorized in low group as we seen in figure 4, in answering question number $1, \mathrm{~S} 2$ is less precise in constructing evidence that the real sequence of numbers has one limit. The subject designed the right strategy in carrying out proof using the contradiction method, but was not right in defining the limit of the sequence. Based on the problem-solving steps taken, the subject did not complete the reasons for taking these steps. For example, do not complete the explanation or the supporting theorem used why choose $\varepsilon=\frac{1}{3}\left|x_{b}-x_{a}\right|$.

\subsection{Ability To Make Conclusions From Statement}

From the answer of student in answering question number one which categorized in high group as we seen in figure 2 , the subject draws the conclusion that $x_{n} \in V_{\varepsilon}\left(x_{1}\right) \cap V_{\varepsilon}\left(x_{2}\right)$, is obtained, while these results contradict the statement that $V_{\varepsilon}\left(x_{1}\right)$ and $V_{\varepsilon}\left(x_{2}\right)$ are foreign to each other, consequently the assumption that $x_{1} \neq x_{2}$ is wrong. So $\lim \left(x_{1}\right)=\lim \left(x_{2}\right)=x_{1}=x_{2}$.

For the question number 4 , student which categorized in moderate group as we seen in figure 3, S3 wrote the completion step is incomplete.Based on the completion steps written by the subject, it can be seen that the conclusion obtained by the subject $x=-\frac{7}{3}$ and $x=\frac{7}{5}$ and written $H P=\left\{-\frac{7}{3}, \frac{7}{5}\right\}$.

Furthermore, from the answer of student which categorized in low group as we seen in figure 4 , in answering question number 1 , The subject is less precise in constructing evidence that the real sequence of numbers has one limit. The subject designed the right strategy in carrying out proof using the contradiction method, but was not right in defining the limit of the sequence. Based on the problem-solving steps taken, the subject did not complete the reasons for taking these steps. For example, do not complete the explanation or the supporting theorem used why choose $\varepsilon=$ $\frac{1}{3}\left|x_{b}-x_{a}\right|$.

\subsection{The Validity An Argument}

From the answer of student in answering question number one which categorized in high group as we seen in figure 2, it showed that the subject checked the answer. It can be seen from the conclusions obtained, the subject reconnects the reasons with the previously proposed definitions / theorems.

For the question number 4, student which categorized in moderate group as we seen in figure 3, the subject did not re-check the steps to solve the problem based on the correct definition.

Furthermore, from the answer of student which categorized in low group as we seen in figure 4, in answering question number 1 , the subject is not correct in drawing conclusions from solving the problem. It happened because the conclusions are not linked back to those asked in the questions. Because the pattern of problem solving uses the contradiction method, the conclusion should show the statement on the conclusion contradicting the statement on the presupposition.

\subsection{Ability To Find Patterns Or Properties Of A Mathematical Phenomenon To Make Generalizations}

From the answer of student in answering question number one which categorized in high group as we seen in figure 2 , it showed the subject has found a pattern in solving the problem by using the definition of $\varepsilon$ or $V_{\varepsilon}(x)$ in proving that a sequence has a single limit. It indicates that the student have understood about the concept of limit.

For the question number 4, student which categorized in moderate group as we seen in figure 3 , it showed the subject can find patterns in solving the absolute value equation problems, but it is not correct in defining and finding the solution area.

Furthermore, from the answer of student which categorized in low group as we seen in figure 4 , in answering question number 1 , the subject had not found a pattern in proving a theorem using contradiction. So that the conclusions drawn in solving the problem are also wrong. . It indicates that students have not been able to do abstract and manipulative thinking processes in solving proving questions.

Subjects who have high mathematical reasoning ability is better than subjects who have in the medium and low groups. This can be seen from the subject's ability to fulfill all reasoning indicators, so as to get a better indication in solving HOTS-based real analysis questions. Beside that the student was able to solve problems correctly and coherently starting from formulating problem solving strategies, mentioning definitions and theorems correctly, solving problems 
correctly and being able to draw conclusions from mathematical problems correctly.

Students with moderate reasoning abilities are able to carry out the problem solving stages quite well. However, analyzing and using logic skills in solving problems is still not quite right. In addition, the ability to count is quite good even though it makes mistakes in calculations. Not all test questions can be answered by every subject.

Students with low mathematical reasoning skills in solving real analysis problems have a tendency to carry out mathematical reasoning less well. These students are not able to meet all indicators of mathematical reasoning. Students are not able to understand the questions well, so that students cannot complete the questions asked.

The results of this study are in line with [13], [14] statement that reasoning and proofing abilities are very important for building students' understanding of mathematical concepts. Leithner in [8] mentions that reasoning is the foundation of mathematics, unfortunately, students at all grade levels find it difficult in mathematical reasoning problem including undergraduate students of mathematical majors. Therefore, mathematical reasoning skills must be given attention during the lecturing process of real analysis courses and should be regularly improved with proving mathematical theorems.

\section{CONCLUSION}

Based on the mathematical reasoning ability measured in this study, it can be concluded that $16.7 \%$ of students were categorized as having low reasoning, that is presenting a mathematical statement in writing, $16.7 \%$ of students were categorized as having moderate reasoning, that is able to make a conjecture and perform mathematical manipulation, and $66.7 \%$ of students were categorized as having high reasoning, which is able to make a conjecture, to perform a mathematical manipulation, to provide the reasons or evidence for the solution and drawing a conclusion.

\section{AUTHORS' CONTRIBUTIONS}

The first author was contributed in making the instrument, collecting data, analyzing data, and making the report of this research. Meanwhile the second author was contributed in helping the first author in collected data, analyzing data and making the report of this research.

\section{ACKNOWLEDGMENTS}

Gratitude is conveyed to the Bung Hatta University Research and Community Service Institute (LPPM) for funding this research through the 2020 Higher Education Excellence Lecturer Research
(PDUPT) scheme with contract letter No. 068-05 / LPPM-Research / Hatta / IX-2020 7 September 2020.

\section{REFERENCES}

[1] Sukirwan, D. Darhim, and T. Herman, "Analysis of students' mathematical reasoning," J. Phys. Conf. Ser., vol. 948, no. 1, 2018, DOI: https://doi.org/10.1088/1742-6596/948/1/012036.

[2] I. Mardiyah, Suhito, and M. F. Safa'atullah, "Analysis of mathematical reasoning ability of junior high school students of grade VII viewed from cognitive style on problem based learning with mind mapping," Unnes J. Math. Educ., vol. 7, no. 2, pp. 122-128, 2018, DOI: https://doi.org/ 10.15294/ujme.v7i2.24883.

[3] N. Agustyaningrum, Y. Hanggara, A. Husna, A. M. Abadi, and A. Mahmudii, "An analysis of students' mathematical reasoning ability on abstract algebra course," Int. J. Sci. Technol. Res., vol. 8, no. 12, pp. 2800-2805, 2019.

[4] A. W. Jufri, D. Setiadi, and Sripatmi, "Scientific reasoning ability of prospective student teacher in the excellence program of mathematics and science teacher education in University of Mataram," J. Pendidik. IPA Indones., vol. 5, no. 1, pp. 69-74, 2016, DOI: https://doi.org/ 10.15294/jpii.v5i1.5792.

[5] M. Saleh, R. Charitas, I. Prahmana, and M. Isa, "Improving the Reasoning Ability of Elementary School Student Through the Indonesian Realistic," J. Math. Educ., vol. 9, no. 1, pp. 41-54, 2018.

[6] I. M. Arnawa, Y. Yerizon, and S. Nita, "Improvement Students' Level of Proof Ability in Abstract Algebra Trough APOS Theory Approach," Int. J. Sci. Technol. Res., vol. 8, no. 7, pp. 128-131, 2019.

[7] M. Mueller and C. Maher, "Learning to reason in an informal math after-school program," Math. Educ. Res. J., vol. 21, no. 3, pp. 7-35, 2009, DOI: https://doi.org/10.1007/BF03217551.

[8] R. Rahmawati, M. Mardiana, and T. Triyanto, "Analysis of Studentsr Mathematical Reasoning Ability in Solving Mathematics Problem," vol. 262, no. Ictte, pp. 311-314, 2018, DOI: https://doi.org /10.2991/ictte-18.2018.57.

[9] A. Selden and J. Selden, "Validations of proofs considered as texts: Can undergraduates tell whether an argument proves a theorem?," J. Res. Math. Educ., vol. 34, no. 1, pp. 4-36, 2003, DOI: https://doi.org / 10.2307/30034698. 
[10] F. Adamura and V. D. Susanti, "Penalaran Matematis Mahasiswa Dalam Memecahkan Masalah Analisis Real Berdasarkan Kemampuan Berpikir Intuitif," J. Math. Math. Educ., vol. 8, no. 2, pp. 156-172, 2018, DOI: https://doi.org/ 10.20961/jmme.v8i2.25852.

[11] A. R. As'ari, M. Ali, H. Basri, D. Kurniati, and S. Maharani, Mengembangkan HOTS (High Order Thinking Skills) Melalui Matematika, I. Malang: Universitas Negeri Malang, 2019.

[12] W. B. N. Dosinaeng, “Analysis of students' higher order thinking skills in solving basic combinatorics problems," Math Didact. J. Pendidik. Mat., vol. 5, no. 2, pp. 133-147, 2019, DOI: https://doi.org /: 10.33654/math.v5i2.611.

[13] N. Novia and R. Riandi, "The analysis of students scientific reasoning ability in solving the modified lawson classroom test of scientific reasoning (MLCTSR) problems by applying the levels of inquiry," J. Pendidik. IPA Indones., vol. 6, no. 1, pp. 116-122, 2017, DOI: https://doi.org/: 10.15294/jpii.v6i1.9600.

[14] W. R. Sandy, S. Inganah, and A. F. Jamil, "The Analysis of Students' Mathematical Reasoning Ability in Completing Mathematicalproblems on Geometry," Math. Educ. J., vol. 3, no. 1, p. 72, 2019,DOI:https://doi.org/:10.22219/mej.v3i1.84 23. 